\title{
O ADOECIMENTO DA HUMANIDADE E O LIMITE PARA A EXISTÊNCIA HUMANA: A MORTE E O SUICÍDIO NA PERSPECTIVA DO DIREITO A SAÚDE MENTAL
}

\author{
Janaína Machado Sturza* \\ Rodrigo Tonel**
}

\section{RESUMO}

A existência humana, apesar de todos os fatores que circundam a contemporaneidade, apresenta um limite - seja pela morte, seja pelo suicídio. O presente artigo tem por objetivo fomentar a reflexão acerca do fenômeno do suicídio enquanto ato intencional de matar a si mesmo, estabelecendo uma interlocução com o adoecimento da humanidade, especialmente na perspectiva do direito à saúde mental. Através de um estudo bibliográfico, tendo como método de abordagem o hipotético dedutivo, verificou-se que as políticas públicas de prevenção a este fenômeno devem ser propostas sob o olhar multifatorial e multicausal, alicerçada em acepções da saúde mental e do biodireito.

Palavras-Chave: Biodireito; direito a saúde; morte; políticas públicas; suicídio.

\section{THE SICKENING OF HUMANITY AND THE LIMIT FOR HUMAN EXISTENCE: DEATH AND SUICIDE THROUGH THE PERSPECTIVE OF THE RIGHT TO MENTAL HEALTH}

\begin{abstract}
Human existence, despite all the factors surrounding contemporary times, has a limit - either by death or by suicide. This article aims to foster the reflection on the phenomenon of suicide as an intentional act of killing oneself, establishing a dialogue with the sickening of humanity, especially from the perspective of the right to mental health. Through a bibliographical study, using the hypothetical deductive approach, it's been verified that the public policies for prevention over this phenomenon, should be proposed under the multifactorial and multicausal perspective, based on the meanings of mental health and biolaw.
\end{abstract}

Keywords: Biolaw; right to health; death; public policies; suicide.

\section{INTRODUÇÃO}

\footnotetext{
* Pós doutora em Direito pelo Programa de Pós-Graduação em Direito da Universidade do Vale do Rio dos Sinos -UNISINOS. Doutora em Direito pela Escola Internacional de Doutorado em Direito e Economia Tullio Ascarelli, da Universidade de Roma Tre/Itália. Mestre em Direito pela Universidade de Santa Cruz do Sul UNISC. Especialista em Demandas Sociais e Políticas Públicas também pela UNISC. Graduada em Direito pela UNISC. Professora na Universidade Regional do Noroeste do Estado do Rio Grande do Sul - UNIJUÍ, lecionando na graduação em Direito e no Programa de Pós-Graduação em Direito - Mestrado e Doutorado. Integrante do grupo de pesquisa Biopolítica e direitos humanos (certificado pelo CNPq). Email: janasturza@hotmail.com

** Mestrando no Programa de Pós-Graduação em Direitos Humanos -Mestrado e Doutorado, da Universidade Regional do Noroeste do Estado do Rio Grande do Sul - UNIJUI, Bolsista da Coordenação de Aperfeiçoamento de Pessoal de Nível Superior - CAPES. Bacharel em Direito pela UNIJUÍ. Email: tonelr@yahoo.com
} 
Até onde tem-se conhecimento, nossa existência - a existência humana, é limitada, ou seja, não podemos viver eternamente, uma vez que nosso corpo físico está condicionado a viver temporariamente devido a fatores biológicos. Morrer é um processo natural da vida, assim como nascer é um acontecimento natural para iniciar o ciclo de vida de um ser vivo.

Todavia, enquanto um nascimento é muitas vezes celebrado com felicidade, a morte é vista com tristeza e geralmente evitada com todos os esforços. Todo ser vivo está destinado a morrer no final de sua vida. Assim, todos nós nascemos, crescemos e vivemos sabendo que um dia morreremos. É verdade que podemos adiar nossa morte através das tecnologias que temos, através de medicamentos e tratamentos, mas não podemos evitar, eternamente, a morte.

No entanto, a partir deste cenário, eis que podemos enfrentar a possibilidade de acabar com nossas vidas - não mais através da morte por causas naturais ou situações inevitáveis, mas através do suicídio enquanto ato intencional de matar a si mesmo.

Neste contexto, o presente artigo objetiva fomentar a reflexão acerca do fenômeno do suicídio e o crescente aumento de sua ocorrência na sociedade contemporânea, estabelecendo uma interlocução com o adoecimento da humanidade, especialmente na perspectiva do direito à saúde mental. Discute-se, igualmente, a importância de políticas públicas voltadas a sua prevenção e decorrente proteção ao direito humano à saúde e consequentemente à vida.

Atualmente, o fenômeno do suicídio destaca-se nas pautas de debates na ceara da saúde pública e, mais especificamente, da saúde mental, no sentido de identificar as principais causas que levam as pessoas a abreviação de sua existência. De igual modo, os debates seguem na tentativa de se construir um entendimento acerca dos temas que envolvem os limites da existência humana e por consequência o suicídio, tais como a autonomia e liberdade do ser humano em dispor ou não pelo seu corpo físico, ou seja, as discussões relativas ao direito à vida e à morte e a liberdade de escolha e/ou opção voluntária do indivíduo pela morte, frente a intervenção do Estado na vida do indivíduo, mediante o dever de proteger a vida.

Assim, portanto, a discussão envolta ao tema ora proposto encontra sua relevância nos campos do direito à saúde, do biodireito e das políticas públicas, além da contribuição jurídica e social no que diz respeito a construção dos fundamentos e marcos teóricos e 
normativos - afinal, o suicídio deve ser um tema de analise multidisciplinar, especialmente diante do preocupante aumento das taxas de mortes provindas deste fenômeno.

Desta forma, através do método hipotético dedutivo e da técnica de pesquisa bibliográfica, verificou-se como essencial e urgente iniciativas de formulação e implementação de políticas públicas de prevenção a este fenômeno, as quais devem ser propostas sob um olhar multifatorial e multicausal, levando-se em consideração aspectos sociais, políticos, midiáticos, culturais e até mesmo religiosos, e, sobretudo, alicerçadas em acepções do biodireito e do direito à saúde mental, no intento de resguardar a vida e a própria espécie humana.

\section{A inexpugnabilidade da morte: argumentos sobre um evento inadiável}

A morte é, por natureza, um acontecimento inexpugnável. Um evento inadiável. Nossa vida se assemelha a lógica da ampulheta, isto é, da mesma forma que a areia da ampulheta vai escoando vagarosamente até que esteja completamente transpassada para a outra face do artefato, assim também acontece com a vida. Somos condenados a um tempo de vida. Findado este tempo, então, não nos resta mais nada a não ser a morte. Para a maioria das pessoas, a areia da ampulheta da vida escoa naturalmente até o seu fim. Já, para algumas pessoas - e não poucas - a areia da ampulheta da vida escoa mais rápido do que naturalmente escorreria devido a interferência e interesse do indivíduo, ou seja, sua vida acaba antes do que outrora naturalmente acabaria e, aqui, a referência é ao suicídio.

A morte sempre foi considerada um acontecimento misterioso e enigmático para os seres humanos, sendo que, as religiões, as crenças, as concepções filosóficas e a própria ciência tentam explicá-la, mas nunca conseguem, de fato, decifrá-la. O fato é que, para a grande maioria da humanidade, a morte é vista como algo ruim. Mas, seria este acontecimento realmente algo que possa ser considerado como ruim?

Por uma perspectiva filosófica, a morte não pode ser ruim para a pessoa que morreu, ela é ruim para aqueles que continuam vivos, ou seja, as pessoas que amavam o morto como familiares e amigos. Para estas pessoas a morte representa algo ruim justamente porque impossibilita a continuação ou permanência de um vínculo de interação que outrora dispunham com aquele que no presente momento se encontra morto (KAGAN, 2012). 
Alguns dirão que a morte é ruim para aquele que morre. Notadamente que, neste aspecto, não estamos discutindo o processo de morrer/morte. Até porque neste, é mais fácil de identificar se é bom ou ruim. Poderíamos citar o exemplo de um indivíduo que é atacado por ferozes e famintos tigres de bengala e, por consequência, tem os membros de seu corpo despedaçados, resultando, por fim, em seu óbito. Obviamente que, numa situação assim, o processo de morte pode ser considerado ruim, isto porque ser despedaçado por tigres até a morte é, sem sombra de dúvida, um processo muito doloroso. Por outro lado, poderíamos ter um processo de morte que pode ser considerado bom. É o caso, por exemplo, de um indivíduo que morre dormindo sem sentir dores ou agonias.

Contudo, este não se traduz no âmago da discussão que aqui propomos. O que queremos refletir é se a morte é ruim ou boa. Neste sentido, portanto, poderíamos dar enfoque no indivíduo que está morto. Seria a morte ruim para aquele que está morto?

Se partirmos do pressuposto de que todo aquele que está morto já não mais existe, então a morte não pode ser considera nem ruim e nem boa. Teríamos que mudar a pergunta e indagar: Seria a não existência ruim para aquele que já não existe mais?

Ora, para uma não existência não há que se falar em dor e prazer, tristezas e alegrias, derrotas e vitórias. Esses valores só acontecem para aquele que existe. Então, como a morte e/ou não existência pode ser ruim ou boa? Para Kagan (2012, p. 212, tradução nossa), “[...] o que é ruim em estar morto é que você não consegue mais experimentar e aproveitar as várias coisas boas da vida".

A essa perspectiva e/ou argumento, daríamos o nome de deprivation account, ou conta de privação (KAGAN, 2012). Para Kübler-Ross (1975) é e sempre será muito difícil aceitarmos a morte. Até mesmo para aquelas pessoas que aprenderam a aceita-la como parte integral do ciclo da vida.

Para Lucretius (n.d.), o período logo após nossa morte não é o único período que simboliza ou se traduz em uma não existência. Existe um outro período de não existência. Basta refletirmos um pouco e perceberemos que se trata de um período pretérito ao nosso nascimento, ou seja, antes de nosso nascimento não existíamos. Até mesmo, talvez, um infinito período de não existência. Assim, se pelo pressuposto do depravation account a morte é considerada ruim porque nos priva de continuarmos aproveitando as coisas boas da vida, por que, então, não questionamos esse período quase que infinito ou eterno de não existência antes de nosso nascimento? Porque se a morte nos coloca de volta naquela condição de não 
existência a que estávamos submetidos antes de nosso nascimento, então, qual o problema com a morte?

Aparentemente, não há nada ruim acerca da eternidade de nossa não existência antes de nosso nascimento. Assim, por este seguimento, se não há nada de errado com a não existência antes de nosso nascimento, analogicamente, não há nada de errado com a não existência pós morte (LUCRETIUS, n.d.).

Para Kübler-Ross (1975, p. 5, tradução nossa), "a morte é parte integrante da vida, tão natural e previsível quanto nascer. Mas enquanto o nascimento é motivo de celebrações, a morte tornou-se uma questão temida e indecifrável a ser evitada por todos os meios possíveis em nossa sociedade moderna".

Contudo, não é bem assim. Tratamos diferentemente e assimetricamente estes dois polos de não existência justamente porque quando morremos deixamos de viver, isto é, perdemos algo que tivemos - nossas vidas -, ao passo que, durante o período que antecede nosso nascimento, ainda não tivemos a oportunidade de vivenciar ou experimentar a vida para, então, concluirmos que sua perda é algo ruim.

Tomando por premissa o argumento do depravation account, de que a morte é ruim porque nos priva das coisas boas da vida, então, seria a solução a imortalidade? Aqui, igualmente, entraríamos em uma longa discussão filosófica. Mas sabendo que uma das alternativas frente a morte seria a de vivermos para sempre, teríamos que pesar se a imortalidade seria algo bom ou ruim. E, se chegássemos a conclusão de que, por exemplo, a imortalidade fosse algo ruim, então a morte seria algo bom, na medida em que nos salvaria da imortalidade (KAGAN, 2012). Já para Szasz (2011, p. 6, tradução nossa), “[...] não há objetivamente "boa morte" ou "morte ruim"; só há morrer - ou viver - considerada "boa" ou "má", de acordo com os valores da pessoa que faz o julgamento".

Nesse sentido, importante se faz destacar que nesta reflexão sobressalta a ideia e o exercício de liberdade no que diz respeito às vidas e corpos, afinal, morrer ou viver, sob a perspectiva do suicídio, está diretamente relacionado à liberdade de dispor do próprio corpo.

\section{Liberdade de dispor do próprio corpo: viver ou morrer?}

Na sociedade ocidental contemporânea onde a ideia e exercício de liberdade é um fator característico e muito aparente, a maioria das pessoas presumem serem autônomas e 
soberanas no que diz respeito às suas vidas e corpos. Assim, por exemplo, quando alguém é assassinado, se destaca que esse mesmo alguém foi privado de seu direito à vida. Contudo, quando alguém se suicida, frequentemente se diz que isso se sucedeu em razão de que este indivíduo provavelmente sofria de algum tipo de doença mental. Entrementes, neste último caso, não estaria este indivíduo exercendo seu direito de auto propriedade? Não estaria ele constituído de liberdade para dispor de sua própria vida e de seu corpo, e fazer o que bem entender com sua existência diante daquela premissa?

Já dizia John Stuart Mill (1859, p. 13, tradução nossa) em sua obra On Liberty, “[...] sobre si mesmo, sobre seu próprio corpo e mente, o indivíduo é soberano.”

Muitas pessoas parecem inaptas a entenderem ou aceitar o fato de que algumas pessoas escolhem morrer por seu próprio desejo e vontade, e por seus próprios meios. Para aquelas o suicídio é resultado de distúrbios mentais, ou seja, não se leva em consideração a hipótese de acidente, patriotismo, heroísmo, auto sacrifício, ou até mesmo uma forma de martírio, dentre outras. Com isso, se percebe que tudo fica rotulado a doenças mentais (SZASZ, 2011).

De acordo com Szasz (2011, p. 8, tradução nossa), “[...] como qualquer ação humana, o suicídio pode ser considerado bom, ruim ou indiferente; elogiado ou condenado; recomendado ou proibido; ou aceito como aceitamos o clima."

Para Hillman (2009), a interferência da justiça interpessoal ou justiça social em detrimento da justiça pessoal sempre esteve muito aparente no decorrer de toda a história do direito, principalmente, no ocidente. Isso porque, a lei não reconhece o suicídio como um direito, ou uma liberdade de escolha proveniente da autonomia e soberania do indivíduo sobre o seu corpo. Os seres humanos são o principal elemento constituinte do corpo social e, nesta lógica, cada vez que um ser humano se suicida, analogicamente, se poderia dizer que um membro desse corpo social é amputado, por isso, o suicídio é algo repudiado pela sociedade e pelo Estado. Com isso, "[...] a lei não estabeleceu um tribunal que aceite petições de suicídio, de modo que não há maneira de se optar por morte, a não ser infringindo a lei. O suicida é culpado e não pode jamais provar sua inocência" (HILMAN, 2009, p. 39). Entrementes, sob este prisma a lei nos obriga a viver, mesmo em desacordo com nossas vontades, e isso revela que nossa liberdade é limitada, ela não é plena.

Obviamente que morrer implica efeitos nos variados ramos do Direito. Atemo-nos ao Direito Penal por um momento. Até 1961, o suicídio sempre foi considerado um crime para a 
maioria das nações. Sempre fora justificado e comparado com o homicídio, uma espécie de auto homicídio (MINOIS, 2018). Para a maioria das nações o ato de matar alguém sempre foi considerado um crime e, normalmente, se tem uma respectiva dosagem punitiva. Contudo, existem situações em que matar alguém não incorre em um crime e, em alguns casos, não há aplicação de penalidades, ou as penas podem ser consideravelmente reduzidas. Os exemplos clássicos aqui seriam o instituto da legítima defesa, o homicídio culposo, o estado de exceção, entre outros. Contudo, o suicídio sempre fora considerado um crime injustificável. Isso nos leva a compreensão de que, “[...] pode-se matar outras pessoas de muitas maneiras e sob muitas alegações sem se transgredir a lei; mas não se pode nunca, sob hipótese alguma, matarse de maneira justificável ou desculpável”(HILLMAN, 2009, p. 39). A exceção, entretanto, se dava somente para aquele indivíduo que sofresse de algum tipo de distúrbio mental, que o incapacitasse de raciocinar e de tomar decisões em sã consciência, justamente porque se demonstrava inapto e incompatível a aceitação e observação de um contrato social firmado essencialmente pela razão. Na sociedade contemporânea, no entanto, poucos países ainda matem o suicídio e a tentativa como um crime tipificado (MISHARA, WEISSTUB, 2016).

Agora, por quais razões as pessoas se matam? Normalmente, porque a vida está tão ruim que não mais vale a pena ser vivida. E, portanto, se já não mais vale a pena ser vivida, parece ser melhor morrer. É certo que, cada pessoa tem suas próprias razões ao optar pela morte.

Na tentativa de explicar o porquê as pessoas se suicidam, Szasz (2011), irá comparar o suicídio como uma forma de emigração, isto é, o indivíduo que se suicida, ele está emigrando da terra dos vivos para a terra dos mortos. Ele deixa para trás sua família e sociedade, e sabemos que isso não é uma decisão impensada e tranquila, pelo contrário, quando alguém deixa sua família e o ambiente onde vive para ir residir em uma outra terra, com costumes diferentes, com pessoas diferentes e até mesmo com um idioma diferente, toda essa separação traz muita dor e tristeza.

Pensar no suicídio como uma expressão de liberdade é, sem sombra de dúvida, um argumento que pesa bastante. Contudo, se faz necessário mencionar que grande maioria das pessoas que optam pelo suicídio não o fazem como uma expressão de suas liberdades, mas sim, como uma alternativa frente aos variados problemas que as afligem.

Portanto, para a maioria dos casos de suicídio na contemporaneidade, as pessoas não se matam porque querem gozar de suas liberdades, pelo contrário, elas querem continuar 
vivendo, mas como não encontram alternativas para seus problemas, optam pelo suicídio. Assim, nas palavras de Hume (1777, p. 10, tradução nossa), “[...] eu acredito que nenhum homem jogou fora a vida enquanto ela ainda valesse a pena ser mantida".

Além disso, frustrações, tristezas e dores também são partes constituintes da vida humana. Só que quando estamos tristes, frustrados ou com dores, nossa capacidade de reflexão é prejudicada consideravelmente. Deste modo, quando optamos pelo suicídio, temos que ter consciência real da decisão que estamos tomando. Se nossa capacidade de discernimento é confundida pela dor, tristeza ou frustração, então, não temos como saber se o suicídio realmente é coisa certa a fazer.

Neste contexto, poderíamos exemplificar com um dos argumentos frequentemente utilizados a fim de justificar os casos de eutanásia, isto é, a ideia de sofrimento insuportável. Isto porque as razões que levam as pessoas a se matarem variam de indivíduo para indivíduo. Em outras palavras, a órbita de subjetividades que corroboram para a constituição psicológica de cada indivíduo é diferente, não são iguais. E, portanto, qualquer pessoa pode entender seu caso próprio como sofrimento insuportável. É difícil, portanto, justificar afirmando que o sofrimento insuportável de um indivíduo não é digno do sofrimento insuportável de outro. Esse argumento é expansivo e pode ser evocado até mesmo para situações onde inexiste real sofrimento insuportável ou não se pode apura-lo (YUILL, 2013).

Portanto, evidencia-se, nesta conjuntura, que o suicídio é um fenômeno multicausal e multifatorial - em outras palavras, resta claro que o suicídio nem sempre ocorrerá necessariamente por razões patológicas.

\section{0 suicídio como um fenômeno multicausal e multifatorial}

Sabemos que o suicídio é um fenômeno multicausal e multifatorial, ou seja, o suicídio nem sempre ocorrerá necessariamente por razões patológicas. Existem suicídios que são motivados por questões sociais, para isto basta mencionar a análise sociológica de Émile Durkheim (2011), quando o referido autor propõe uma reflexão sociológica acerca do fenômeno do suicídio, isto é, o suicídio como um fato social.

$\mathrm{Na}$ definição Durkheimiana, "[...] chama-se suicídio todo o caso de morte que resulta direta ou indiretamente de um ato, positivo ou negativo, realizado pela própria vítima e que ela sabia que produziria esse resultado (DURKHEIM, 2011, p. 14, grifo do autor). 
Através desta definição, Durkheim (2011) esclarece o real sentido do suicídio. Ainda aponta que não se deve confundir o suicídio com seus parentes próximos, o que ele chama de suicídios embrionários, ou seja, situações que se distanciam gradualmente do suicídio propriamente dito. Durkheim cita alguns exemplos como a morte de um homem que se expõe ao perigo e risco de morte com o objetivo de salvar seu semelhante; o indivíduo que por negligência não dá o devido cuidado a sua saúde e compromete sua vida, tendo como resultado a morte.

Para evidenciar que sua perspectiva, Durkheim (2011) analisa os fatores-extra sociais do suicídio, elencando essencialmente dois, quais sejam, as disposições orgânico-psíquicas e a natureza do meio físico. No que diz respeito ao primeiro, este está associado à loucura, podendo ser proveniente de uma espécie de loucura especial, ou consequência de vários tipos de loucuras. Assim, para os defensores dessa hipótese, todo o suicida é um indivíduo delirante e/ou alienado, o que, portanto, deixa claro o entendimento de que o suicídio é um fenômeno individual.

Durkheim (2011), entretanto, rejeita essa hipótese e argumenta que se o suicídio é uma loucura, então a questão estaria resolvida e poderíamos afirmar que todo suicida é um louco. Ora, “[...] grande número de mortes voluntárias não entram em nenhuma dessas categorias; a maioria delas tem motivos que não deixam de ter fundamento na realidade. Não se pode, portanto, sem fazer mau uso das palavras, considerar todo suicida um louco" (DURKHEIM, 2011, p. 44).

Durkheim (2011, p. 111) analisa os fatores cósmicos, ou seja, a temperatura, duração dos dias, variações sazonais. E, por fim, conclui que "[...] se a temperatura fosse a causa fundamental das oscilações que constatamos, o suicídio deveria variar regularmente com ela. Ora, isso não acontece. As pessoas se matam muito mais na primavera do que no outono [...].”

Pelo critério de eliminação, Durkheim (2011) acredita que o suicídio deva depender de causas sociais, o que, consequentemente, leva a constituí-lo como um fenômeno coletivo. Diante disso, ele, então, propõe três tipos de suicídios sociais. São eles: suicídio egoísta, suicídio altruísta e suicídio anômico.

O primeiro tipo refere-se ao tipo de suicídio causado pela fragilização e/ou enfraquecimento dos laços que conectam o indivíduo e a sociedade a qual faz parte. Deste modo, “[...] o suicídio varia na razão inversa do grau de integração dos grupos sociais de que o indivíduo faz parte" (DURKHEIM, 2011, p. 258). 
Com isso, uma sociedade é fortemente integrada previne esse tipo de suicídio, justamente porque obstaculizaria o indivíduo de dispor de si mesmo conforme sua própria vontade e seu capricho. A sociedade cria nele certa dependência na medida em que o impõe deveres e serviços a serem cumpridos. Contudo, quando o indivíduo opta por desertar sua obrigação com a sociedade, esta, por sua vez, já não tem autoridade suficiente para impor sua soberania e impedir que aquele se mate. Isso ocorre quando o indivíduo já não encontra mais razões para continuar suportando as misérias de sua existência.

Em outras palavras, o indivíduo que se encontra inserido solidariamente em um grupo social que o faz sentir que sua vida vale a pena ser vivida em razão dos interesses que são compartilhados, se torna como um laço que o amarra a existência e previne que a abrevie, simplesmente porque atenua suas contrariedades privadas.

Portanto, poderíamos afirmar que na perspectiva Durkheimiana ocorre uma dualidade humana, ou seja, o indivíduo físico e o indivíduo social, sendo que, este último se sobrepõe aquele. Ora, para Durkheim (2011), o ser humano por razões psicológicas não consegue viver sem que exista algo que lhe faça viver. Dito de outra forma, nós seres humanos necessitamos nos ligar a algum objeto que nos faça perceber o porquê, ou que simplesmente dê algum sentido para que nossas existências valham a pena ser vividas. Pois quando não vislumbramos outro objetivo além de nós mesmos, podemos concluir que todo o tipo de esforços que façamos estão destinados a perecer no vácuo do universo. E, por si só, isso já é motivo suficiente para que desistamos de nossas vidas.

Assim, o suicídio não ocorre somente pelo estado de melancolia e tristeza que nos afoga e nos persegue constantemente. Até porque, tristezas, dores, derrotas, frustrações todo mundo experimenta no decorrer da vida, e esses estados são naturalmente elementos constituintes de nossas existências. Contudo, no momento que deliberamos por apertar o gatilho, puxar a corda ou nos jogarmos do alto de um arranha céu, não é só por causa das derrotas que eventualmente estão desencorajando nossa vontade de viver, mas é porque já não nos é possível participar do jogo da vida, em outras palavras, já não temos mais a possibilidade de tentar alcançar objetivos, justamente porque já não temos objetivos para serem alcançados.

A partir dessa percepção, Durkheim (2011) fez uma abordagem acerca das sociedades religiosas e suas respectivas relações com o fenômeno do suicídio, elencando as 
três principais de sua época e de seu entorno, quais sejam, o catolicismo, o protestantismo e o judaísmo.

$\mathrm{Na}$ primeira delas, ele verifica que indivíduos católicos se suicidam menos do que indivíduos protestantes. Isso porque, no catolicismo temos um culto previamente preparado, composto por uma hierarquia já determinada. Já, os judeus gozam ainda de menor propensão ao suicídio do que os católicos. Sabemos, todavia, que ambos os sistemas religiosos, demonstram aversão ao suicídio e, mesmo proíbem e punem moralmente aqueles indivíduos que assim eventualmente procederem. O enigma, então, é descobrirmos por que em um deles o suicídio se mostra mais intenso.

O livro sagrado do católico é a Bíblia, porém, esta é colocada nas mãos de autoridades hierarquicamente definidas e os fiéis já recebem a interpretação das escrituras sagradas de forma pronta. O católico, outrossim, não necessita fazer nenhum exame de consciência ou interpretação teológica.

Já, no que diz respeito ao protestante, este é o próprio autor de sua fé, pois a Bíblia é colocada em suas mãos e nenhuma interpretação exterior lhe é imposta, justamente, porque no culto protestante não há uma autoridade hierárquica estabelecida. O sacerdote e o fiel encontram-se em uma situação, poderíamos dizer, de igualdade.

Nas palavras de Vares (2017, p. 25), para os protestantes, a “[...] noção de livrearbítrio concede ao indivíduo maior liberdade de pensamento e ação, da qual resulta uma espécie de "individualismo religioso" tanto no plano da crença quanto no plano da hierarquia institucional".

Assim, essa liberdade de reflexão seria, então, a mola propulsora para o suicídio, precisamente porque conduz os crentes a um tipo de individualismo o que, por consequência, afrouxa os vínculos destes com a sociedade religiosa a que fazem parte e, o resultado final, portanto, se dá com um número maior de suicídios quando comparados ao catolicismo.

Quanto ao judaísmo, Durkheim (2011, p.189) explica que “[...] consiste essencialmente num corpo de práticas que regulamentam minuciosamente todos os detalhes da existência e deixam muito espaço para o julgamento individual.” E, é exatamente por existir pouco espaço para o julgamento individual que o judeu se suicida menos do que o catolicismo e o protestantismo, por dispor de menor oportunidade de análise pessoal, exame de consciência e auto interpretação do Torá. 
No que diz respeito ao casamento, Durkheim (2011), ao tempo de sua investigação, analisou e conclui que a sociedade matrimonial é responsável por gerar, o que ele chama de coeficiente de preservação do suicídio. Através do levantamento de dados estatísticos, ele pode demonstrar que os indivíduos que se encontravam na condição de casados se matavam menos do que indivíduos solteiros; que os casados com filhos se matavam menos do que os casados sem filhos; constatou que o casamento protege mais aos homens do que as mulheres de abreviarem suas existências; que os viúvos, se suicidam mais do que os casados, porém, menos do que os solteiros; que as mulheres viúvas se matam menos do que os homens viúvos.

Na sequência, Durkheim (2011) aborda o chamado suicídio altruísta. Poderíamos dizer que este tipo de suicídio é o polo oposto do suicídio egoísta, ou seja, uma espécie de antônimo deste. Ora, no suicídio egoísta o indivíduo se mata pela desvinculação ou fragilização dos laços que o unem a sua sociedade, ou seja, pelo desprendimento que o liga a sua sociedade, levando-o a uma individualização excessiva. Ocorre que, no suicídio altruísta o inverso acontece, isto é, quando o indivíduo se integra demasiadamente a sua sociedade, ele também se mata.

Durkheim (2011) constatou este tipo de suicídio mais frequente em sociedade primitivas e em regimes militares. Onde o indivíduo abrevia voluntariamente sua vida em virtude de um bem maior, qual seja, a sociedade em que ele está intimamente ligado. Ao deliberar a abreviação de sua existência através do suicídio, o indivíduo entende que sua morte, ou mesmo, o sacrifício de sua vida, acarretará algum tipo de benefício para a sociedade. Em muitos casos, o indivíduo sente que o suicídio é um dever para com a sociedade. Ele é treinado a renunciar a vida, exemplo mais comum desse treinamento, é o do militar, porque ele é treinado a renunciar sua vida por um bem maior, qual seja, o bem coletivo.

E, por fim, o suicídio anômico. A anomia se traduz pela falta de regulação social. Neste tipo de suicídio, a principal causa é a perturbação de equilíbrio social que inclina o indivíduo a morte voluntária, mesmo que essa perturbação se traduza em aumento de progresso ou conforto para a sociedade (DURKHEIM, 2011).

Durkheim (2011), por fim, concluiu que, a sociedade que mais eficazmente preveniria o suicídio é a sociedade laboral. Isso porque gastamos grande parte do tempo de nossas vidas exercendo algum tipo de atividade laboral e, consequentemente, as pessoas que 
nos estão mais próximas são nossos colegas de trabalho. E, além disso, eles são os que melhor nos compreendem em períodos de dificuldades e tristezas.

Essa variável é tão verdadeira que até mesmo em nossa sociedade contemporânea, grupos de profissionais de determinadas áreas reúnem-se a fim de dialogar e se auto confortarem. Exemplo disso é o caso do Lawyers with Depression, website criado por Dan Lukasik, dedicado a dar suporte a todos os atuantes da área jurídica que se tornam depressivos em virtude da profissão que exercem, ou seja, advogados, juízes, estudantes de Direito, promotores, entre outros (LAWYERS WITH DEPRESSION, n.d.). Podemos afirmar, por exemplo, que um advogado é capaz de entender o estresse e as dificuldades que seu colega enfrenta, dentro do mundo jurídico, melhor que um psicólogo.

Por fim, Hillman (2009, p. 35), afirma que “[...] o suicídio é uma tendência coletiva do organismo social, com existência própria, manifestando-se através da cobrança em um certo tributo anual". Deste modo, ele se dá exclusivamente por causas sociais que variam em determinados meses do ano, determinados grupos, determinadas regiões, determinados sexos e determinadas idades, reforçando a ideia do adoecimento emocional da humanidade.

\section{$4 \mathrm{O}$ adoecimento emocional da humanidade}

Nossa sociedade contemporânea é caracterizada pelo progresso quando comparada a períodos pretéritos. De acordo com Pinker (2019, p. 4, tradução nossa), temos

[...] recém-nascidos que viverão mais de oito décadas, mercados transbordando de
comida, água limpa que aparece com um estalar de dedo e desperdício que
desaparece com outro, pílula que apaga uma infecção dolorosa, filhos que não são
enviados a guerra, filhas que podem andar pelas ruas em segurança, críticos dos
poderosos que não são presos ou fuzilados, conhecimento e cultura do mundo
disponíveis no bolso da camisa [...].

Atualmente, podemos ter em nossa lista de amigos no Facebook personalidades como Jackie Chan, Maicon Jordan, Vandana Shiva, Diego Hypólito, o presidente do Sri Lanka, e até mesmo, alguns dos autores que aqui estamos utilizando para elaborar esta pesquisa! Enfim, isso nos faz perceber as opções múltiplas que temos em mãos com os avanços tecnológicos, especialmente, na área das tecnologias de comunicação.

A tecnologia aliada com a Internet tem facilitado muito nossas vidas. Se, por exemplo, temos interesse em aprender idiomas, basta navegar um pouco e nos depararemos com uma infinidade de cursos online, materiais, aulas etc. Se queremos aprender tocar algum 
tipo de instrumento musical basta procurar aulas no YouTube ou partituras no Google e, com um pouco de tempo e dedicação, estaremos tocando o instrumento desejado. Quando queremos fazer pesquisas sobre determinado assunto, através da Internet, podemos entrar em centenas de bibliotecas virtuais, periódicos, blogs etc. Os exemplos parecem infindáveis. É fatídico que a tecnologia e a Internet têm revolucionado o mundo nos últimos anos.

De acordo com Pinker (2019), portanto, nossa humanidade experimenta um momento onde nunca em sua história foi registrado um índice tão elevado de progresso, isto é, somos mais felizes, saudáveis, vivemos mais do que nossos antepassados, avançamos para a igualdade de direitos, temos democracia, somos mais informados, estamos mais seguros, não vivemos em um momento marcado por guerras, enfim, nossa condição atual é muito boa.

Contudo, muitos pensadores discordam com essa perspectiva de progresso, afirmando que vivemos em um momento apocalíptico, atribuindo a culpa ao capitalismo tecnológico, o qual, tem amaldiçoado as pessoas, tornando-as extremamente individualistas, egocentristas, consumeristas, materialistas, insensíveis, ostentatórias, atomizadas, entre outros tantos adjetivos (WÜNSCH et al., 2016).

Dentre esses autores, poderíamos citar Bauman (2004), o qual desenvolveu com o conceito de liquidez de nossa sociedade contemporânea, onde afirma, a título de ilustração, que trocamos os relacionamentos reais pelos virtuais, rompemos as relações sociais reais pelas virtuais criando maior isolamento e individualismo entre as pessoas.

Lipovetsky (2007), por sua vez, aponta para uma sociedade de hiperconsumo, que tem como característica principal a busca da felicidade através do consumo de objetos. Consequentemente, esses tipos de compreensões apenas fazem com que as pessoas mergulhem cada vez mais no abismo da solidão.

Com a entrada de tecnologias de comunicação, que, em tese, teriam o condão de fortalecer os laços sociais, dispomos apenas de um ilusório fortalecimento destes laços, pois aquelas produzem o efeito de fragilizá-los. É bem verdade que podemos trazer diversas personalidades em nossas listas de amigos no facebook - como apontamos no exemplo anterior -, no entanto, somos, muitas vezes, rodeados por números virtuais e não por amigos reais.

Outro autor que aponta para o adoecimento emocional da humanidade é o sulcoreano Byung-Chul Han (2015), trazendo a compreensão de uma sociedade que se encontra física e psiquicamente esgotada - Síndrome do Burnout -, marcada por uma onda de 
positividade e perfeccionismo, que leva ao surgimento e a sobreposição de doenças neurológicas sobre os demais tipos de doenças epidêmicas. Isso tudo contribui decisivamente para a intensificação do fenômeno do suicídio em nossa sociedade contemporânea.

Ademais, basta checarmos o site da Organização Mundial da Saúde, para observarmos que, atualmente, cerca de quase um milhão de pessoas se suicidam todos os anos. Para sermos mais precisos o número gira em torno de 800.000 mil óbitos de suicídio por ano, isto é, o mesmo que um suicídio a cada 40 segundos. Ainda assim, existe a indicação de que a cada 1 suicídio consumado, outros 20 foram tentados. O suicídio pode ocorrer em qualquer momento da vida, todavia, encontra-se em segundo lugar no ranking das causas de morte entre jovens de 15 a 29 anos no mundo (WORLD HEALTH ORGANIZATION, 2018). Os números são, inegavelmente, alarmantes. No entanto, a referida fonte sugere que grande maioria desses suicídios poderiam ser evitados.

No caso brasileiro, entre os anos de 2007 e 2016, foram registrados cerca de "[...] 106.374 óbitos por suicídio. Em 2016, a taxa chegou a 5,8 por 100 mil habitantes, com a notificação de 11.433 mortes por essa causa.” (MINISTÉRIO DA SAÚDE, 2018, n.p.).

No Brasil, observamos uma acentuada diferença com relação ao gênero. De acordo com o Ministério da Saúde (2017), o suicídio é a terceira principal causa de morte entre pessoas do sexo masculino, e a oitava principal causa de morte entre pessoas do sexo feminino.

Além disso, de acordo com Jaen-Varas et al. (2019), no Brasil, o fenômeno do suicídio aumentou em $24 \%$ entre os adolescentes brasileiros que residem em grandes cidades, e no geral 13\%, dos anos de 2006 a 2015. As razões principais desse aumento do suicídio no Brasil são as mudanças socioeconômicas dos últimos anos, o excessivo uso da Internet e falta de políticas públicas de prevenção. A utilização indiscriminada da Internet, principalmente, no que diz respeito, a participação e exposição assídua de adolescentes em redes sociais aumenta a sensação de isolamento e pode estimular os adolescentes ao suicídio.

Esse isolamento e entristecimento da humanidade configura o suicídio Durkheimiano chamado egoísta, porque enfraquece os laços que unem o indivíduo a sua sociedade. Ele representa um afrouxamento da estrutura social, ou seja, a fragilização dos laços grupais que nutrem o corpo social. Ele é responsável pela desintegração social, ferindo as balizas sociais e, consequentemente, desestruturando a sociedade. Assim, tal fenômeno é considerado um inimigo da sociedade e, portanto, sua ocorrência deve ser prevenida e evitada. 
A prevenção, então, seria basicamente trazer de volta ao grupo social aquele indivíduo que se afastou. Isso porque, o isolamento individual para fora do grupo social é a determinante que leva o indivíduo a tendência suicida. Deste modo, a prevenção sociológica do suicídio é o fortalecimento grupal. Juntos somos mais fortes, juntos tornamo-nos imunes ao suicídio.

Assim, portanto, a prevenção do suicídio deve ser tratada na coletividade, sem esquecer, entretanto, das ações voltadas a implementação e fortalecimento das políticas públicas de proteção à saúde mental, e, por consequência, à vida.

\section{Suicídio, direito à saúde mental e políticas públicas: realidade e perspectivas futuras}

Sabemos da barbárie que ocorreu na década de 1960, no Centro Hospitalar Psiquiátrico de Barbacena, mais conhecido por Hospital Colônia, resultando na morte de cerca de 60 mil pessoas, além dos abusos incomensuráveis que os pacientes daquele lugar sofreram e, que, mais tarde ganhou o pseudônimo de Holocausto Brasileiro (ARBEX, 2013).

A partir daí, com a reforma psiquiátrica brasileira através anuência do nosso país na Declaração de Caracas de 1990, isto é, documento que serve de marco para as reformas em atenção na saúde mental nas Américas (DECLARAÇÃO DE CARACAS, 1990), que culminou com o advento da Lei N. ${ }^{\circ} 10.216$ de abril de 2001 - mais conhecida por Lei Antimanicomial - que dispõe sobre a proteção e preservação aos direitos daqueles indivíduos acometidos por transtornos mentais (BRASIL, 2001) e, posteriormente, em ações mais práticas como é o caso da Resolução n. ${ }^{\circ} 3.088$ de 23 de dezembro de 2011, com a instituição da Rede de Atenção Psicossocial - RAPS -, que vem a dar amparo para os indivíduos que manifestam algum tipo de sofrimento mental, assim como, adicionalmente, para aqueles com necessidades decorrentes do uso de drogas e álcool (BRASIL, 2011).

Ademais, campanhas como o janeiro branco, que é dedicada a fortalecer as discussões que giram em torno dos temas relacionados a Saúde Mental, buscando sensibilizar as mídias, poderes públicos e privados, bem como, a sociedade no geral, a respeito da importância de “[...] políticas públicas, recursos financeiros, espaços sociais e iniciativas socioculturais empenhadas(os) em valorizar e em atender as demandas individuais e coletivas , direta ou indiretamente, relacionadas aos universos da Saúde Mental." (JANEIRO BRANCO, n.d., n.p.). 
Do mesmo modo, o setembro amarelo, campanha de prevenção ao suicídio que ocorre no mundo todo, sob o slogan Falar é a melhor solução!, com o objetivo de abrir espaço para a discussão da temática e suas formas de prevenção (SETEMBROAMARELO, 2019).

A política Nacional de Saúde Mental, portanto, é uma ação do governo federal em prol daquelas pessoas que sofrem transtornos mentais oriundos de causas diversas, incluindo dependentes de substâncias psicoativas, como são os casos clássicos do uso de drogas e álcool. Fornece a assistência e o acolhimento devidos não só aos doentes, como também, seus familiares.

Em períodos de crises, essas pessoas poderão ser atendidas e/ou internadas em um dos Centros de Atenção Psicossocial - CAPS - e, receber os serviços da Rede de Atenção Psicossocial - RAPS, sendo aquele um dos pontos que compõem esta.

Dentro do viés jurídico, recentemente, o governo federal sancionou a Lei no 13.819 , de 26 de abril de 2019, que cria a Política Nacional de Prevenção da Automutilação e do Suicídio. Essa política tem como principais objetivos a preservação da saúde mental e a prevenção a violência autoprovocada. $\mathrm{O}$ Art. $3^{\circ}$, em seus incisos, estabelece claramente todo o rol de objetivos. No entanto, para o contexto deste estudo, destacamos a importância dos incisos IV, VI e VII (BRASIL, 2019).

No inciso IV, é possível vislumbrar a previsão de garantia em relação ao atendimento psicossocial daqueles indivíduos que manifestem sofrimento psíquico, bem como aqueles que demonstram ideação suicida, tentativas e automutilação (BRASIL, 2019).

O inciso VI refere-se a ampla informação e conscientização social com o objetivo de sensibilizar a sociedade para a relevância da temática. E, o inciso VII, onde é possível perceber o esforço para a promoção intersetorial de prevenção ao suicídio, ou seja, “[...] envolvendo entidades de saúde, educação, comunicação, imprensa, polícia, entre outras.” (BRASIL, 2019, n.p.).

A referida lei, também, estabelece notificação compulsória sempre que as instituições se depararem com casos possíveis ou concretos de violência autoprovocada. Deste modo, de acordo com o Art. $6^{\circ}$, inciso I, estabelecimentos de saúde públicos e privados deverão notificar as autoridades sanitárias. Aditivamente, no inciso II do referido artigo, estabelecimentos de ensino públicos e privados deverão comunicar ao conselho tutelar. $\mathrm{O} \S 3^{\circ}$ do referido artigo, acrescenta que, essa notificação terá caráter sigiloso (BRASIL, 2019). 
O Art. $4^{\circ}$ preleciona a respeito da manutenção do serviço telefônico fornecido pelo Centro de Valorização da Vida - CVV, qual seja, uma associação civil sem fins lucrativos, fundada em São Paulo no ano de 1973, que “[...] presta serviço voluntário e gratuito de apoio emocional e prevenção do suicídio para todas as pessoas que querem e precisam conversar, sob total sigilo e anonimato" (CVV, 2019, n.p.). O $\S 1^{\text {o }}$ do referido artigo, ainda dispõe, que serão adotadas outras formas de comunicação, levando em consideração os meios mais utilizados pela população na atualidade, ampliando ainda mais o serviço com o objetivo de alcançar mais pessoas que estejam necessitando de ajuda.

Cabe, notoriamente, ressaltar que o direito à saúde é reconhecido pela Declaração Universal dos Direitos Humanos em seu Art. 25 (UNITED NATIONS, 1948), na Constituição Federal de 1988, nos Arts. $6^{\circ}$ e 196, sendo que, neste último, "a saúde é direito de todos e dever do Estado, garantido mediante políticas sociais e econômicas que visem à redução do risco de doença e de outros agravos e ao acesso universal e igualitário às ações e serviços para sua promoção, proteção e recuperação".

Neste contexto, a Política Nacional de Prevenção da Automutilação e do Suicídio é, sem sombra de dúvidas, um importante passo rumo à prevenção de mortes por suicídio e promoção da saúde.

\section{CONCLUSÃO}

A saúde é um direito de todos e um dever do Estado. Todavia, a saúde não deve ser confundida simplesmente com a ausência de doenças - seu conceito é muito mais amplo e abrangente, deve ser compreendida como o bem-estar físico, mental e social. Portanto, seguindo este ideário, devemos prevenir o suicídio não somente sob a perspectiva física e mental, através da medicalização e hospitalização do indivíduo suicida, mas também sob a perspectiva social e jurídica, através da formulação e implementação de políticas públicas de saúde mental, capazes de fomentar e indicar determinantes sociais e marcos regulatórios sanitários, que de fato - e não somente de direito, garantam o direito humano à saúde, protegendo a vida e a própria existência humana.

Notadamente, a interpretação equivocada de que todo o suicida é um louco, pecador ou imoral, causa extrema estigmatização e rotulagens, gerando constrangimentos na vida social, familiar e profissional do indivíduo e, essas situações, ainda contribuem na 
intensificação da intolerância a sua vida. A sociedade, muitas vezes por falta de informação, ao invés de encontrar meios para prevenir e evitar o suicídio, acaba literalmente atuando como instigadora deste - tudo isso, em algumas ocasiões, aliada à falta de conhecimento, sensibilidade e solidariedade. É mister, antes de tudo, reeducar a sociedade.

Ainda assim, diante de todas as dificuldades e desafios, é sempre importante acreditar na mudança, pois quando se amarra alguém - contenção física, através de métodos como o uso da camisa de força, por exemplo, morre com ele(a) sua dignidade. Além disso, para alcançar a qualidade na saúde mental dos indivíduos, é importante que haja acolhimento e amor. Os profissionais de saúde, assim como toda a sociedade, devem ter orelhas de elefantes e olhos de águia para dar atenção e suporte aquelas pessoas que necessitam de ajuda. É necessário e urgente, portanto, discutir o tema do suicídio, abandonando o individualismo e incentivando o espírito de solidariedade e cooperação humana.

Portanto, o suicídio, enquanto um fenômeno compreendido como ato intencional de matar a si mesmo, deve ser analisado por uma gama muito ampla de fatores e causas, e sua prevenção, do mesmo modo, há que ser proposta de maneira multifatorial e multicausal. Podemos, assim, prevenir os suicídios através de políticas públicas centralizadas na saúde, no biodireito e na educação, que se voltem a promover cidadania e não intolerância. Nas escolas, trabalhar a valorização da vida. Na mídia, campanhas de esclarecimento. Na saúde, maior capacitação, treinamento e preparo aos profissionais. Na legislação, restringir o acesso a meios letais. São essenciais as iniciativas que comunguem políticas públicas e envolvimento da sociedade, com esforços, práticas e ações governamentais ou não governamentais, que incorporem formas múltiplas de prevenção, como são os casos dos RAPS, dos CAPS, do CVV, das campanhas setembro amarelo e janeiro branco - tudo no intento de combater o adoecimento da humanidade e, por consequência, combater a abreviação da existência humana através do suicídio.

\section{Referências}

ARBEX, Daniela. Holocausto Brasileiro. São Paulo: Geração Editorial, 2013.

BAUMAN, Zygmunt. Amor líquido: sobre a fragilidade dos laços humanos. Trad.: Carlos Alberto Medeiros. Rio de Janeiro: Jorge Zahar, 2004. Disponível em:< http://static.tumblr.com/jh0avtj/8xdooienw/amor_liquido_-_zygmunt_bauman.pdf $>$. Acesso em: 11 ago. 2019. 
BRASIL. Lei no 13.819, de 26 de abril de 2019. Disponível em:< http://www.planalto.gov.br/ccivil_03/_ato2019-2022/2019/lei/L13819.htm>. Acesso em: 12 ago. 2019.

BRASIL. Ministério da Saúde. Gabinete do Ministro. Portaria no 3.088, de 23 de dezembro de 2011. Disponível em:< http://bvsms.saude.gov.br/bvs/saudelegis/gm/2011/prt3088_23_12_2011_rep.html>. Acesso em: 07 ago. 2019.

BRASIL. Lei N. ${ }^{0} \mathbf{1 0 . 2 1 6}$ de 6 de abril de 2001. Disponível em:< http://www.planalto.gov.br/ccivil_03/leis/leis_2001/110216.htm>. Acesso em: 07 ago. 2019.

BRASIL. Constituição da república federativa do Brasil de 1988. Disponível em:< http://www.planalto.gov.br/ccivil_03/constituicao/constituicaocompilado.htm>. Acesso em: 12 ago. 2019.

CVV. O cvv. Disponível em:< https://www.cvv.org.br/o-cvv/>. Acesso em: 07 ago. 2019.

DECLARAÇÃO DE CARACAS. 1990. Disponível em:< http://www.abrasme.org.br/resources/download/1358516130_ARQUIVO_DeclaracaodeCarac as.pdf>. Acesso em: 07 ago. 2019.

DURKHEIM, Émile. O suicídio: estudo de sociologia. Trad.: Mônica Stahel. $2^{\circ}$ ed. São Paulo: Editora WMF Martins Fontes, 2011.

HAN, Byung-Chul. The burnout society. Stanford, California: Stanford University Press, 2015.

HILLMAN, James. Suicídio e alma. Trad.: Sônia Maria Caiuby Labate. Petrópolis, RJ: Vozes, 2009.

HUME, David. On suicide. England: Penguin Books - Great Ideas, 1777.

JAEN-VARAS, Denisse. et al. The association between adolescent suicide rates and socioeconomic indicators in Brazil: a 10-year retrospective ecological study. Brazilian Journal of Psychiatry, Feb 18, 2019. Disponível em:<http://www.scielo.br/scielo.php?script=sci_arttext\&pid=S151644462019005003105\&lng=en\&nrm=iso\#B03>. Acesso em: 05 ago. 2019.

JANEIRO BRANCO. Janeiro branco: por uma cultura da saúde mental. Disponível em:< https://janeirobranco.com.br/projeto-janeiro-branco/>. Acesso em: 08 ago. 2019.

KAGAN, Shelly. Death. New Haven and London: Yale University Press, 2012.

KÜBLER-ROSS, Elisabeth. Death: the final stage of growth. New Jersey: A Spectrum Book, 1975.

LAWYERS WITH DEPRESSION. Stress, anxiety and depression in the legal profession.

Disponível em:< http://www.lawyerswithdepression.com/>. Acesso em: 05 ago. 2019. 
LIPOVETSKY, Gilles. A felicidade paradoxal: ensaio sobre a sociedade do hiperconsumo. Trad.: Maria Lúcia Machado. São Paulo: Companhia das Letras, 2007.

LUCRETIUS. On the nature of things. Trad.: Cyril Bailey. Disponível em:< http://files.libertyfund.org/files/2242/Lucretius_1496_Bk.pdf>. Acesso em: 09 jun. 2019.

MILL, John Stuart. On liberty. 1859. Disponível em:< https://eet.pixelonline.org/files/etranslation/original/Mill,\%20On\%20Liberty.pdf>. Acesso em: 03, Jun. 2019. MINISTÉRIO DA SAÚDE. Novos dados reforçam a importância da prevenção do suicídio. 2018. Disponível em:< http://portalms.saude.gov.br/noticias/agencia-saude/44404novos-dados-reforcam-a-importancia-da-prevencao-do-suicidio>. Acesso em: 05 ago. 2019.

MINISTÉRIO DA SAÚDE. Secretaria de Vigilância em Saúde. Perfil epidemiológico das tentativas e óbitos por suicídio no Brasil e a rede de atenção à saúde. Volume $48, n^{\circ} 30$, 2017.

Disponível em:<

http://portalarquivos2.saude.gov.br/images/pdf/2017/setembro/21/2017-025-Perfilepidemiologico-das-tentativas-e-obitos-por-suicidio-no-Brasil-e-a-rede-de-atencao-asaude.pdf>. Acesso em: 05 ago. 2019.

MINOIS, Georges. A história do suicídio: a sociedade acidental diante da morte voluntária. São Paulo: Editora Unesp, 2018.

MISHARA, Brian L., WEISSTUB, David N. The legal status of suicide: a global review. International Journal of Law and Psychiatry, Volume 44, January-February 2016, Page 54-74. Disponível em:<https://www.sciencedirect.com/science/article/pii/S0160252715001429>. Acesso em: 03 jul. 2019.

PINKER, Steven. The enlightenment now: the case for reason, science and humanism. United Kingdom: Penguin Random Science, 2019.

SZASZ, Thomas. Suicide prohibition: the shame of medicine. New York: Syracuse University Press, 2011.

SETEMBROAMARELO. Falar é a melhor solução. Disponível em:< http://www.setembroamarelo.org.br/>. Acesso em: 12 ago. 2019.

UNITED NATIONS. Universal declaration of human rights. 1948. Disponível em:< https://www.un.org/en/universal-declaration-human-rights/>. Acesso em: 12 ago. 2019.

VARES, Sidnei Ferreira de. O problema do suicídio em Émile Durkheim. Revista do Instituto de Ciências Humanas, PUC Minas, vol. 13, no 18, p. 13-36, 2017. Disponível em:< http://periodicos.pucminas.br/index.php/revistaich/article/view/15869/12785>. Acesso em: 03 ago. 2019.

WORLD HEALTH ORGANIZATION. Latest data on suicide. 2018. Disponível em:< http://www.who.int/mental_health/suicide-prevention/en/>. Acesso em: 05 ago. 2019. 
WÜNSCH, Vera Lúcia. et al. Bioética, teologia e saúde mental: diretrizes de cuidado e prevenção do suicídio. Revista Iberoamericana de Bioética, n. ${ }^{\circ}$ 2, 2016. Disponível em:<https://revistas.comillas.edu/index.php/bioetica-revista-

iberoamericana/article/view/7341/8130>. Acesso em: 12 ago. 2019.

YUILL, Kevin. Assisted suicide: the liberal, humanist case against legalization. New York: Palgrave Macmillan, 2013. 